\title{
Physical phenomena in wildfire modelling
}

\author{
D. Morvan \\ Université de la Méditerranée UNIMECA, \\ de Château Gombert 60 rue Joliot Curie 13453, \\ Marseille cedex 13, France
}

\begin{abstract}
Modeling wildfires is a big challenge in Computational Science. The behavior of fires is governed by very complex physical phenomena including various non linear mechanisms such as: the turbulent transport in the atmosphere, the turbulent mixing between the ambient air and the pyrolysis products resulting from the thermal degradation of the vegetation, the heat transfers by convection and radiation between the flame and the vegetation. During the last decades, progress in the computational resources, allowed the development of a new generation of physical models. This new approach to study the behavior of wildfires is based on the resolution of balance equations (mass, momentum, energy) governing the evolution of the coupled system formed by a vegetation strata with the ambient air located in the vicinity of a fire front. After introducing the main physical phenomena occurring during the propagation of a wildfire, we present some numerical simulations obtained using the FIRESTAR model (EU FP5) for surface fires in grassland and shrubland. Depending on the ratio between the intensity of the wind flow and the buoyant plume above the flame front, the numerical results highlighted two different regimes of propagation: the plume dominated fires and the wind driven fires.
\end{abstract}

Keywords: wildfire behaviour, physical modelling.

\section{Introduction and physical considerations}

Modelling the behaviour of wildfire [1] needs to identify the main physical mechanisms governing the heat transfer between the fire front and the unburned vegetation, necessary to heat and ignite the vegetation and finally to sustain the propagation of the fire. To simulate numerically the behaviour of a wildfire, we have to adapt the mesh size used to discretize the physical domain, to the 
physical length scales characterizing the physical phenomena contributing (more or less) to the heat transfer between the flame front and the vegetation. Two mechanisms were clearly highlighted: the convective and the radiation heat transfer. Depending on the dominant mechanism of heat transfer between the burning zone and the solid fuel (the vegetation), two modes of propagation can be identified: the plume dominated fires (in this case, the propagation of the fire is controlled by the radiation heat transfer), the wind driven fires (the fire is governed by the convection heat transfer) [1-3]. In the first case, the flame is weakly deviated by the wind flow and kept a quasi-vertical trajectory. The gas flow located ahead of the fire front is aspirated by the hot plume and supplies the burning zone in oxygen to sustain the combustion reaction. In the second case, the flames are strongly deviated by the wind flow and impact the unburned fuel located ahead of the fire front.

For the physical models based on a multiphase formulation [1], the vegetation is represented as a volume distribution of solid fuel particles, characterized by the volume fraction $\left(\alpha_{S}\right)$, the surface area to volume ratio $\left(\sigma_{S}\right)$, the density $\left(\rho_{S}\right)$ and the moisture content $\left(\mathrm{t}_{\mathrm{S}}{ }^{\mathrm{h} o \mathrm{o}}\right)$. The absorption coefficient characterizing this equivalent "porous media", is equal to $\frac{\alpha_{S} \sigma_{S}}{4}$, the inverse of this quantity defined the attenuation length scale $\delta_{\mathrm{R}}$, the range of variation of this parameter is as in Table 1.

Table 1: Typical values of the attenuation length scale for various ecosystems.

\begin{tabular}{|c|c|c|c|c|c|}
\hline Fuel & Boreal Forest & Med. Pine Forest & Shrubs & Grass & Fuel bed \\
\hline$\delta_{\mathrm{R}}(\mathrm{m})$ & 4.75 & 0.25 & 0.15 & $0.15-0.5$ & 0.025 \\
\hline
\end{tabular}

Another question concerns the level of accuracy, at which the fuel complex layer must be described. Excepted for some particular situations (grassland for example), real vegetation is highly heterogeneous, composed by many species, each one composed by different solid fuel elements (foliage, twigs, trunk...). Experimental fires carried out in a laboratory (in a dead fuel bed, on a flat terrain, without wind), using an homogeneous fuel bed, showed that the fire residence time (defined as the ratio between the fire front depth and the rate of spread: $\tau_{\text {Fire }}=\frac{L_{\text {Fire }}}{R O S}$ increased sharply as the thickness of the solid fuel particles exceeded $6 \mathrm{~mm}\left(\sigma_{\mathrm{S}}<600 \mathrm{~m}^{-1}\right)$ (see Table 2) [4].

Table 2: Variations of the fire residence time versus the surface area to volume ratio (fire propagating through a dead fuel bed, on a flat terrain, without wind).

\begin{tabular}{|c|c|c|c|c|c|}
\hline$\sigma_{\mathrm{S}}\left(\mathrm{m}^{-1}\right)$ & 600 & 2000 & 5000 & 10000 & 20000 \\
\hline$\tau_{\text {Fire }}(\mathrm{s})$ & 125 & 37 & 15 & 7 & 3 \\
\hline
\end{tabular}


On the field, experimental observations (based on the diameter of the residual charred twigs after the passage of the fire) [5] confirmed that a large fraction of the fine fuel $(90 \%)$ was consumed in the flaming zone. This threshold corresponds exactly to the definition of the $1 \mathrm{H}$ class fuel, used by foresters, to characterize the fine fuel which can reach an equilibrium state (moisture content) with the ambient air, in less than one hour. Considering the time scale separation between fine and coarse fuel, we can assume that only fine fuel particles $(\phi \leq 6 \mathrm{~mm})$ participate effectively to the propagation of the fire. However, concerning the other problem of the emission of green gas during a wildfire (from the combustion of the gaseous pyrolysate and the charcoal), because of the large amount of carbon stored in the thick fuel (branches, trunk...), all the classes of solid fuel particles must be in this case, considered.

It is well known that the external parameter, which affects most significantly the behaviour of a wildfire, is the wind. Consequently the structure of the atmospheric boundary layer flow, above a canopy, must be also considered with some details, to understand the physics of wildfires. Many studies showed that the turbulent flow, inside and above a canopy, presents numerous similarities with the mixing layer flow $[6,7]$. The drag effects resulting from the friction, between the wind and the vegetation, modify the vertical velocity profile (stream wise component) in such a way, forming an inflexion point near the top of the canopy, promoting the development of a Kelvin-Helmoltz instability. The large scale turbulent structures (integral turbulence length scale), affecting most significantly the flow, have a size more or less equal to the depth of the vegetation layer. Assuming a wind velocity flow ranging between 5 and $10 \mathrm{~m} / \mathrm{s}$ and a turbulence intensity ranging between 10 and $40 \%$, we can evaluate roughly the scales of turbulence, as in Table 3 [15].

Table 3: Rough estimations of some physical scales, characterizing the boundary layer flow above a canopy (grass, shrubs or trees).

\begin{tabular}{|l|l|}
\hline Turbulence integral length scale $\mathrm{l}_{\mathrm{t}}(\mathrm{m})$ & $1-10 \mathrm{~m}$ \\
\hline Velocity fluctuation U' $(\mathrm{m} / \mathrm{s})$ & $0.5-10 \mathrm{~m} / \mathrm{s}$ \\
\hline Turbulence Reynolds number $\mathrm{R}_{\mathrm{eT}}$ & $3 \times 10^{4}-2 \times 10^{6}$ \\
\hline Kolmogorov micro-length scale $\eta(\mathrm{mm})$ & $0.1-0.5$ \\
\hline
\end{tabular}

\section{Physical modelling of wildfires behaviour}

The behaviour of wildfires results of very complex phenomena such as the heat transfer by convection and radiation between the fire front and the unburned vegetation, the drying and the decomposition by pyrolysis of the vegetation, the turbulent transport of the pyrolysate by the atmospheric flow, the gaseous combustion in the flaming zone ... This phenomena are highly coupled and are often non-linear. Even if the conservation equations (mass, momentum, energy), governing each part of this system, are well established, because of the lack of information concerning some physical parameters and the sensitivity of such system to initial conditions, it remains very difficult to predict numerically the 
evolution of fires, during a long period of time. It is really a big challenging problem in high performance computing (HPC). This context explains the reasons which have conducted to study firstly the problem of the propagation of wildfires, using empirical [8, 9] or semi-empirical models [10]. These approaches are very fast, they need no great computational means, which explains mainly their success for the development of operational tools [11]. Nevertheless, we must keep in mind that, the empirical laws describing the behaviour of the fire in these models, were extracted generally from small scale fire carried out in a wind tunnel or for relatively weak wind conditions on the field (for safety reasons). The extrapolation of these laws, for more severe wind conditions or for fully heterogeneous vegetation, is not straightforward. The direct application of such model, in real conditions, can generate great errors between the behaviour of the simulated fire and the real fire [12].

During the last decades, more physical approaches were proposed [1, 3, 13, 14]. All consider the problem using a multiphase formulation, consisting in assimilating the vegetation as a porous media, composed with a collection of solid fuel particles interacting with the atmospheric flow under the action of the drag forces. These models include two parts:

- The first one, to describe the evolution of the state of the vegetation and its degradation into gaseous (water vapour and pyrolysis products) and solid (charcoal and ashes) products.

- The second one, to describe the physical phenomena occurring in the atmospheric layer in the vicinity of the fire front.

Even if these new kind of wildfire models, seem to integrate the major part of the physical phenomena, governing the behaviour of a fire, we must keep in mind that a large part of the physics cannot be directly calculated (the ratio between the large and the small length scales is too large, see Table 3), and can be only simulated, introducing some approximations or sub-grid scale models. Despite these remarks, the physical modelling of wildfires is considered, by the scientific community, as very promising. It is considered as the only way to study in details the behaviour of fires at a local scale (less than $500 \mathrm{~m}$ ), to understand some problems, such as: the mechanisms of vertical transition between a surface fire and a canopy, the interaction of a fire front with targets in the wildland urban interface (WUI), the effects of slope and wind upon the heat transfer between the flames and the unburned vegetation, the characterization of the regimes of propagation.

To improve the confidence accorded to the informations and the provided from the numerical simulations, it is also very important to compare these results with experimental data obtained at small scale in a fire wind tunnel [16] or at larger scale on the field for various ecosystems $[17,18]$.

\section{Numerical results obtained using the FIRESTAR model}

To illustrate what kind of information, we can extract from wildfire physical modelling, we have reproduced in this part, some numerical results obtained 
from numerical simulations carried in two ecosystems: a grassland [19] and a Mediterranean shrubland [20].

Table 4: Physical properties characterizing the solid fuel particles SA/V: Surface area to volume ratio, FMC: Fuel moisture content (Grassland on the top and Shrubland).

\begin{tabular}{|l|l|l|l|l|l|}
\hline Eco-system & & SA/V $\left(\mathrm{m}^{-1}\right)$ & $\begin{array}{l}\text { FMC } \\
(\%)\end{array}$ & $\begin{array}{l}\text { Coverage } \\
(\%)\end{array}$ & $\begin{array}{l}\text { Density } \\
\left(\mathrm{kg} / \mathrm{m}^{3}\right)\end{array}$ \\
\hline Grassland & Grass & 4000 & 5 & 100 & 500 \\
\hline Shrubland & Leaves & 5920 & 70 & 100 & 810 \\
\hline Shrubland & $\begin{array}{l}\text { Twigs } \\
(0-2 \mathrm{~mm})\end{array}$ & 2700 & 70 & 100 & 900 \\
\hline Shrubland & $\begin{array}{l}\text { Twigs } \\
(2-6 \mathrm{~mm})\end{array}$ & 1000 & 70 & 100 & 930 \\
\hline Shrubland & Grass & 20000 & 10 & 30 & 440 \\
\hline
\end{tabular}

To assure a sufficient level of accuracy during all the calculation, the computational domain was discretized using an adaptive mesh refinement (AMR), on both side of the pyrolysis front, maintaining a mesh size equal to $0.5 \times \delta_{\mathrm{R}}$ and $1.0 \times \delta_{\mathrm{R}}$ along the vertical and the horizontal direction, respectively. The results shown in Figure 1, represent the temperature field (gas phase) and the velocity vectors, calculated during the propagation of a surface fire in grassland under the same conditions than during the experimental fire campaigns carried out in Australia [17]. These results, obtained for three values of the wind velocity $\mathrm{U}_{\mathrm{W}}$ (evaluated at $2 \mathrm{~m}$ height, above the ground level), illustrate the two regimes of propagation identified previously. For $U_{W}=0.5$ and $3 \mathrm{~m} / \mathrm{s}$, the trajectory of the flame is not to much deviated by the wind flow, the plume above the burning zone entrains, by aspiration, the fresh air located on both side of the flame front. As a consequence of this particular configuration of the flow in the vicinity of the fire, the vegetation located ahead of the burning zone can be relatively "cooled" and the main mechanism which can contribute to sustain the propagation of the fire is the radiation heat transfer between the flames and the vegetation. For $U_{W}=8 \mathrm{~m} / \mathrm{s}$, the situation is completely different, under the action of the wind flow, the flames are sheared and the hot gases are pushed toward the unburned vegetation which is heated by convection heat transfer. A set of calculations was carried out for various wind conditions, the evolution of the rate of spread (ROS) and the fire line intensity (I) as the function of the $10 \mathrm{~m}$ open wind velocity were shown in Figure 2. The present numerical results (FIRESTAR) were compared with experimental data obtained on the field [21], we also added the prediction obtained using two operational empirical (MK5) and semi-empirical (BEHAVE) models respectively used by the forest in Australia and in USA, and some numerical results obtained using a 3D code developed at the LANL (FIRETEC) [22].

We can notice that the order of magnitude for the ROS produced using these different approaches, are quite similar, as far the wind conditions remained 

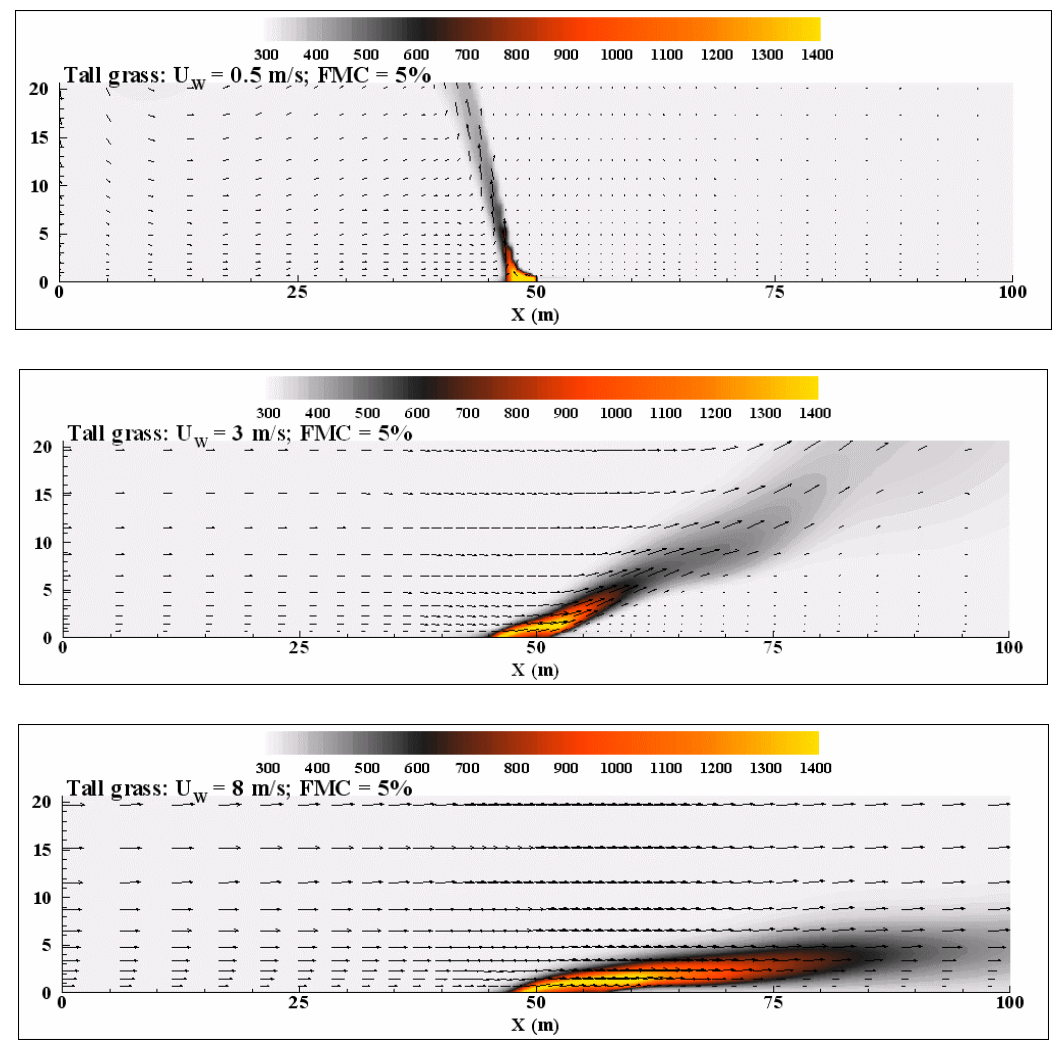

Figure 1: Temperature field and velocity vectors calculated during the propagation of a surface fire through a tall grass [19].
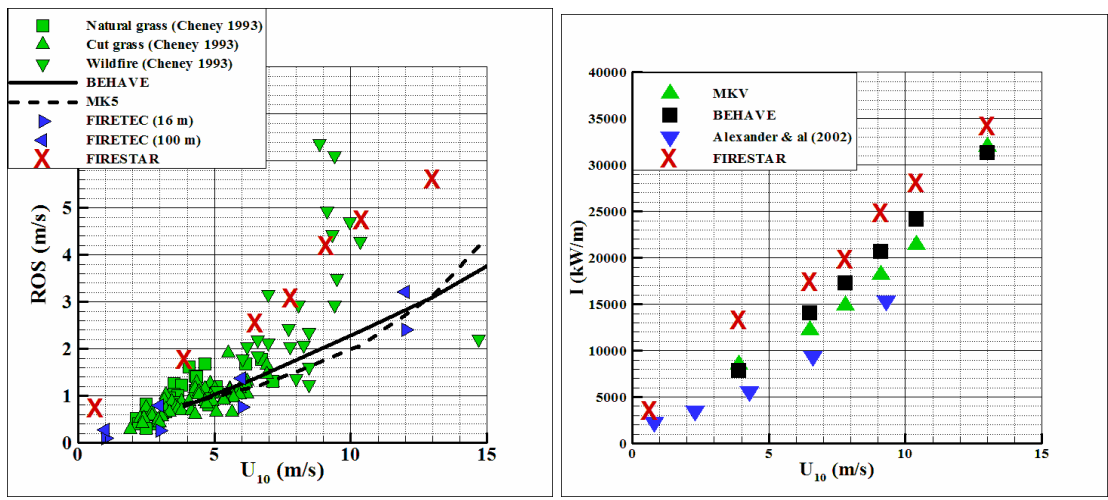

Figure 2: Grassland fires: rate of spread (ROS) (on the left) and fire line intensity (on the right) versus 10 open wind velocity. 
relatively moderate $\left(U_{10}<8 \mathrm{~m} / \mathrm{s}\right)$. For stronger wind conditions $\left(U_{10}>8 \mathrm{~m} / \mathrm{s}\right)$, we observed a relative dispersion between experimental, numerical and empirical results.

These calculations were then extended to heterogeneous vegetation (as shown in Figure 3), a shrubland characteristics of the region of Marseille (in southern France). Two species composed this eco-system: a grass (Brachypodium ramossum, surface cover fraction $=30 \%$ ) and a shrub (quercus coccifera, surface cover fraction $=100 \%$ ) (main physical properties are shown in Table 4). Four families of solid fuel particles were necessary to represent this vegetation: one for the grass, one for the leaves and two for the twigs (we used two classes of diameter: 0-2 $\mathrm{mm}$ and 2-6 $\mathrm{mm}$ ).

The temperature fields calculated in the gaseous phase (Figure 4 on the top) and in the different components of the fuel layer (leaves, fine twigs and grass) are shown in Figure 5. These results highlighted clearly that the gas and the solid fuel particles were not in thermo-dynamical equilibrium. These results confirmed also, the importance to take into account the heterogeneous nature of the vegetation, to reproduce more accurately the process of heat transfer between the hot gases coming from the burning zone and the vegetation. The numerical results obtained for $U_{10}=5 \mathrm{~m} / \mathrm{s}$, showed clearly that the propagation of the fire in this case was mainly piloted by the fine twigs, even if the grass intermixed with the shrub is very dry $(\mathrm{FMC}=5 \%)$, its surface cover fraction $(30 \%)$ was not sufficient to sustain efficiently the propagation of the fire. And in this case, its contribution can be considered as relatively, marginal.

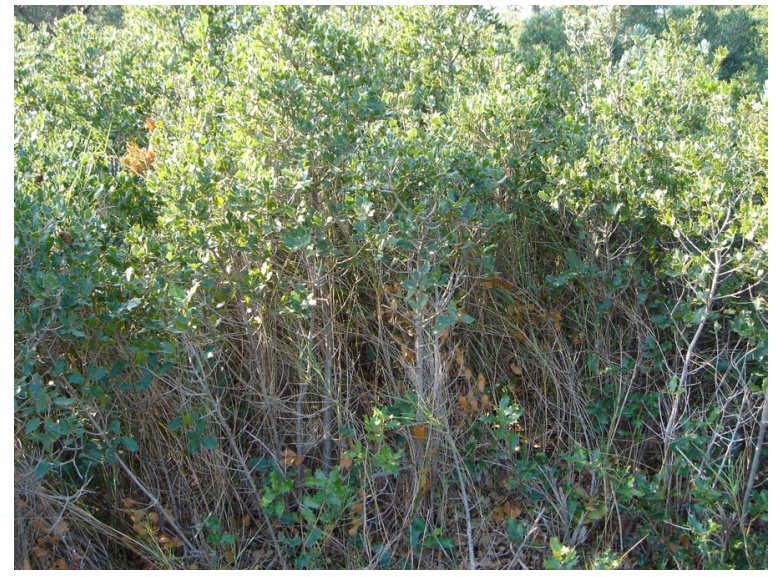

Figure 3: Sample of Mediterranean shrub in the region of Marseille (France): quercus coccifera and brachypodium ramosum.

\section{Conclusions}

We showed that the behaviour of wildland fires can result from various physical mechanisms (heat transfer, turbulent transport, chemical reaction), each ones 

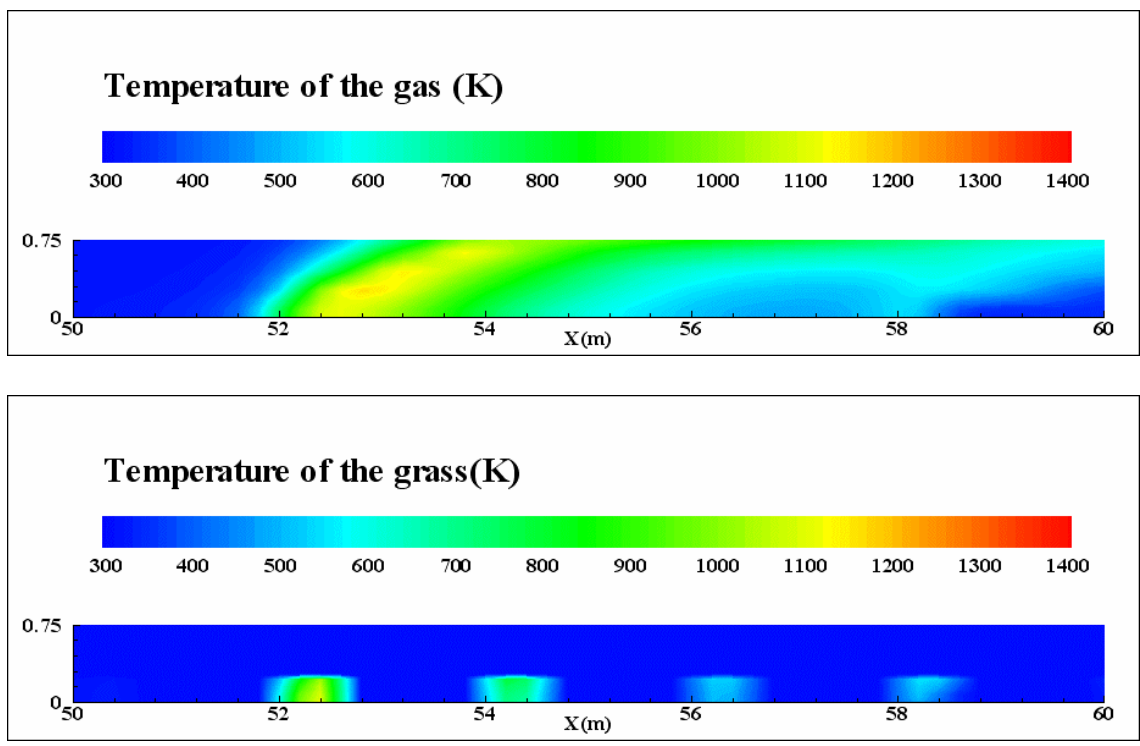

Figure 4: Temperature fields (gas and grass) calculated during the propagation of a surface fire through a Mediterranean shrubland $\left(\mathrm{U}_{10}=5 \mathrm{~m} / \mathrm{s}\right)$.
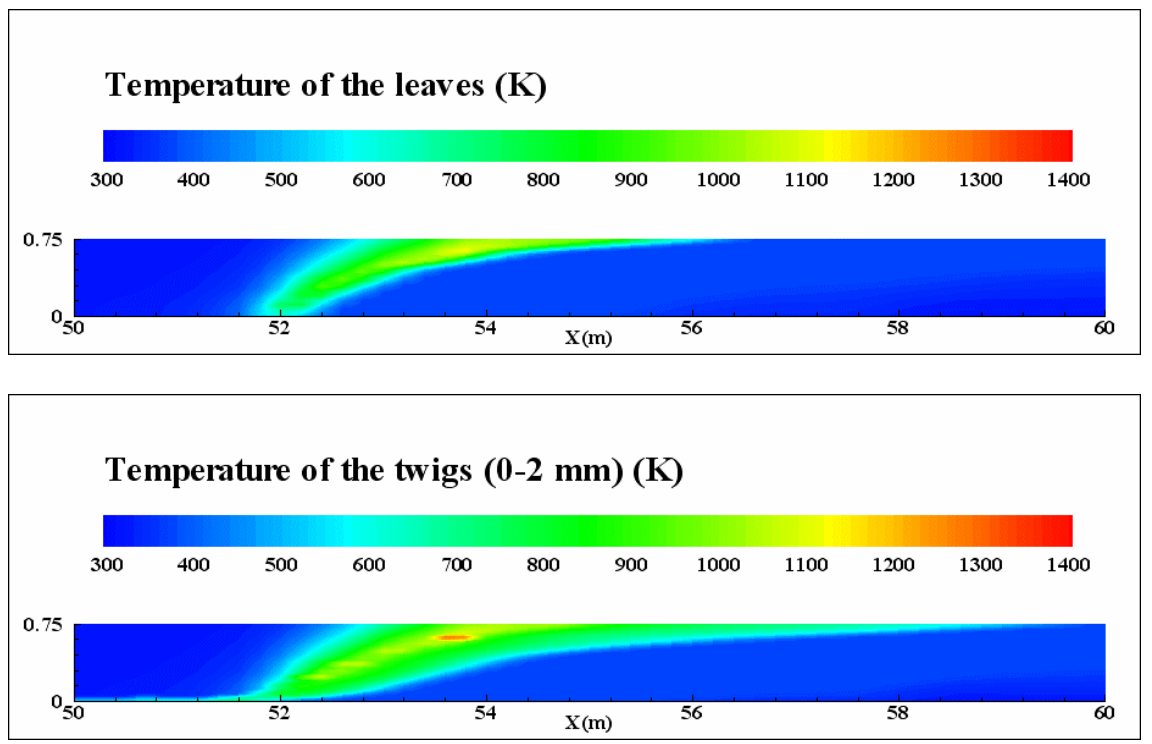

Figure 5: Temperature fields (leaves and thin twigs) calculated during the propagation of a surface fire through a Mediterranean shrubland $\left(\mathrm{U}_{10}=5 \mathrm{~m} / \mathrm{s}\right)$. 
being characterized by length scales distributed on a large spectrum. All these length scales, cannot be completely resolved in a numerical simulation, some of them must be modelized, using more or less physical justifications.

Nevertheless, in complement to experimental investigations, the physical modelling of wildfire presents the main advantage, compared to purely empirical or semi-empirical approaches, to simulate wildfires, without privileging any physical mechanisms, which constitutes the best asset to understand the physics of fires.

\section{References}

[1] Grishin A.M., Mathematical modelling of forest fires and new methods of fighting them. ed. F. Albini Publishing House of the Tomsk State University: Tomsk, 1996.

[2] Pitts W.M., Wind effects on fires. Progress in Energy and Combustion Science, 17, pp. 83-134, 1991.

[3] Morvan D. \& Dupuy J.L., Modeling the propagation of a wildfire through a Mediterranean shrub using a multiphase formulation. Combustion and Flame. 138, pp. 199-210, 2004.

[4] Burrows N.D., Flame residence times and rates of weight loss of eucalypt. forest fuel particles, Int. J. of Wildland Fire.10, pp. 137-143, 2001

[5] Cheney N.P., in: R.H. Gill, R.H. Groves, I.R. Noble (Eds.), Fire and the Australian biota, Australian Academy of Science, Canberra, p. 151, 1981.

[6] Su H.B., Shaw R.H., Paw U K.T., Moeng C.H., Sullivan P.P., Turbulent statistics of neutrally stratified flow within and above sparse forest from large-eddy simulation and field observations, Boundary-Layer Meteorology. 88, pp. 363-397, 1998.

[7] Kaimal J.C. \& J.J. Finnigan, Atmospheric Boundary layer flows. Oxford University Press: New York and Oxford, 1994.

[8] Mc Arthur A.G., Grassland fire danger meter MkIV Forest Research Institute, Forestry and timber bureau, Canberra, 1973.

[9] Mc Arthur AG, Grassland fire danger meter MkV, CSIRO Division of Forest Annual Report 1976-1977 p.58, 1977.

[10] Rothermel, R. A mathematical model for predicting fire spread in wildland fuels, Technical Report, USDA Forest Service Research, INT-115, 1972.

[11] Finney MA, "FIRESITE: Fire Area Simulator-Model Development and Evaluation", RMRS-RP-4, Ogden, UT, 47 p., 1998.

[12] Hanson H.P., Bradley M.M., Bossert J.E., Linn R.R., Younker L.W., The potential and promise of physics-based wildfire simulation. Environment Science Policy, 3, pp. 161-172, 2000.

[13] Linn R.R., Reisner J., Colman J.J., Winterkamp J., Studying wildfire behavior using FIRETEC. Int. J. of Wildland Fire, 11, pp. 233-246, 2002.

[14] Mell W., Jenkins M.A., Gould J.S., Cheney N.P. A physics-based approach to modelling grassland fires. Int. J. of Wildland Fire, 16(1), pp. 122, 2007.

[15] Pope S.B. Turbulent flows. Cambridge University Press, 2000. 
[16] Catchpole W.R., Catchpole E.A., Butler B.W., Rothermel R.C., Morris G.A., Latham D.J., Rate of spread of free-burning fires in woody fuels in a wind tunnel. Combustion Science and Technology 131, pp. 1-37, 1998.

[17] Cheney N.P., Gould J.S., Catchpole W.R., Prediction of fire spread in grasslands. Int. J. of Wildland Fire, 8(1), pp. 1-13, 1998.

[18] Fernandes, P.A.M. Fire spread prediction in shrub fuels in Portugal. Forest Ecology \& Management, 144, pp.67-74, 2001.

[19] Morvan D., Meradji S., Accary G. Physical modelling of fire spread in grasslands. Fire Safety Journal (in press), 2008.

[20] Morvan D., Meradji S., Accary G. Wildfire behaviour study in a Mediterranean pine stand using a physical based model. Combustion Science and Technology, 180(2), pp. 230-248, 2008.

[21] Cheney N.P., Gould J.S., Catchpole W.R. The influence of fuel, weather and fire shape variables on fire spread in grasslands. Int. J. of Wildland Fire, 3(1), pp. 31-44, 1993.

[22] Linn R.R., Cunningham Ph. Numerical simulations of grass fire using a coupled atmosphere-fire model: Basic fire behaviour and dependence on wind speed. Journal of Geophysical Research, 110 (D13107), pp. 1-19, 2005. 